\title{
Correction to: A Novel Idea for Groundwater Resource Management during Megadrought Events
}

\author{
Ameneh Mianabadi ${ }^{1} \cdot$ Hashem Derakhshan ${ }^{1} \cdot$ Kamran Davary $^{1} \cdot$ \\ Seyed Majid Hasheminia ${ }^{1} \cdot$ Markus Hrachowitz $^{2}$
}

Published online: 28 September 2020

(C) Springer Nature B.V. 2020

\section{Correction to: Water Resour Manag https://doi.org/10.1007//11269-020-02525-4}

The original version of this article unfortunately contains an oversight in the spelling of name of one of the cited authors. The correct last name of the author is Langridge, which was misspelled as "Langride" by mistake in the text of the article and in the references. Also, "She" was referred to as "He" in the article.

The authors sincerely apologize for these inadvertent oversights.

Publisher's Note Springer Nature remains neutral with regard to jurisdictional claims in published maps and institutional affiliations.

The online version of the original article can be found at https://doi.org/10.1007/s11269-020-02525-4

Seyed Majid Hasheminia

s.m.hasheminia@gmail.com; Hasheminia@ferdowsi.um.ac.ir

1 Water Science \& Engineering Department, College of Agriculture, Ferdowsi University of Mashhad, P. O. Box 91775-1163, Mashhad, Iran

2 Department of Water Management, Faculty of Civil Engineering and Geosciences, Delft University of Technology, PO Box 5048, Delft, The Netherlands 